\title{
CAPÍTULO 12: A IMPORTÂNCIA DA COBERTURA VEGETAL NO PROCESSO DE EROSÃO E DEGRADAÇÃO DO SOLO NO ENSINO DA GEOGRAFIA
}

\author{
CAPÍTULO 12: LA IMPORTANCIA DE LA COBERTURA VEGETAL EN EL \\ PROCESO DE LA EROSIÓN Y DEGRADACIÓN DEL SUELO EN LA \\ ENSEÑANZA DE LA GEOGRAFÍA
}

\section{CHAPTER 12: THE IMPORTANCE OF VEGETABLE COVERAGE IN THE PROCESS OF EROSION AND SOIL DEGRADATION IN TEACHING GEOGRAPHY}

\author{
Leonardo Nogueira de Sá1; João Paulo Angelo Leite²; Gilson Brandão da Rocha Filho ${ }^{3}$
}

DOI: https://doi.org/10.31692/978-65-88970-05-8.178-192

\begin{abstract}
RESUMO
O solo é algo extremamente necessário para todos os seres vivos do planeta, pois o mesmo permite a manutenção do ecossistema terrestre. Devido ao solo, as plantas absorvem seus nutrientes para sobreviverem no qual o mesmo é essencial para o nascimento e crescimento das plantas, assim como, os seres vivos dependem dele indiretamente para sobreviverem. A referente pesquisa tem como objetivo avaliar a importância da cobertura vegetal para o meio ambiente, tanto para nós seres humanos como para os solos de maneira geral, destacando as formas de degradação do solo e expor aos discentes a sua importância. Diante disso, é necessário um cuidado especial, poluir o solo e o desmata-lo prejudica o seu desenvolvimento, assim como, a fauna e flora de uma região. O solo desprotegido pode sofrer com as ações de desestruturação e desagregação ocasionada pela exposição direta aos raios solares, assim como os impactos das gotas de chuva resultando em erosões. É notório que a cobertura vegetal mantém a sustentabilidade da terra e mantém a umidade do solo, ajudando na decomposição e aumentando a matéria orgânica e nutrientes da terra. O solo serve como proteção e moradia para inúmeras espécies de animais e microrganismos, e a partir dele que os vegetais se desenvolvem fornecendo fonte de energia a toda a cadeia alimentar, garantindo a sobrevivência de diversas espécies. O solo é um componente da paisagem de grande valor para a existência dos seres vivos, porém o ensino deste assunto não vem recebendo a devida importância nas escolas e pouco abordado. Esse estudo tem um enorme valor, pois além de desenvolver o aprendizado sobre a importância dos solos, promove a conservação.
\end{abstract}

Palavras-chave: Educação, Ensino de Geografia, Solo, Vegetação.

\section{ABSTRACT}

Soil is extremely necessary for all living beings on the planet, as it allows the maintenance of the terrestrial ecosystem. Due to the soil, plants absorb their nutrients to survive in which it is essential for the birth and growth of plants, just as living beings depend on it indirectly to survive. This research aims to evaluate the importance of vegetation cover for the environment, both for us humans and for the soil in general, highlighting the forms of soil degradation and exposing the students to its importance. Therefore, it is necessary to take special care, pollute the soil and deforest it, harming its development, as well as the fauna and flora of a region. Unprotected soil can suffer from the actions of disruption and disintegration caused by direct exposure to sunlight, as well as the impacts of raindrops resulting in erosion. It is well known that the vegetation cover maintains the sustainability of the land and maintains the soil moisture, helping with decomposition and increasing the organic matter and nutrients of the land. The soil serves as protection and housing for innumerable species of animals and microorganisms, and from it, vegetables develop, providing energy sources for the entire food chain, guaranteeing the survival of several species. Soil is a component of the landscape of great value for the existence of living

\footnotetext{
${ }^{1}$ Licenciatura em Geografia, Faculdade de Ciências Humanas do Sertão Central, leo nogue

${ }^{2}$ Licenciatura em Geografia, Faculdade de Ciências Humanas do Sertão Central, jp

${ }^{3}$ Geógrafo, Mestre em Gestão Ambiental, Faculdade de Ciências Humanas do Sertão Central, gilsinhogbftf@hotmail.com
} 
beings, however the teaching of this subject has not been given due importance in schools and has been little addressed. This study has enormous value, because in addition to developing learning about the importance of soils, it promotes conservation.

Keywords: Education, Education of Geography, Suelo, Vegetación.

\section{RESUMEN}

El suelo es sumamente necesario para todos los seres vivos del planeta, ya que permite el mantenimiento del ecosistema terrestre. Debido al suelo, las plantas absorben sus nutrientes para sobrevivir en lo que es fundamental para el nacimiento y crecimiento de las plantas, así como los seres vivos dependen de él indirectamente para sobrevivir. Esta investigación tiene como objetivo evaluar la importancia de la cobertura vegetal para el medio ambiente, tanto para los humanos como para el suelo en general, destacando las formas de degradación del suelo y exponiendo a los estudiantes a su importancia. Por ello, es necesario tener especial cuidado, contaminar el suelo y deforestarlo, perjudicando su desarrollo, así como la fauna y flora de una región. El suelo desprotegido puede sufrir las acciones de interrupción y desintegración causadas por la exposición directa a la luz solar, así como los impactos de las gotas de lluvia que resultan en erosión. Es bien sabido que la cubierta vegetal mantiene la sustentabilidad del terreno y mantiene la humedad del suelo, ayudando a la descomposición y aumentando la materia orgánica y los nutrientes del terreno. El suelo sirve de protección y albergue a innumerables especies de animales y microorganismos, y a partir de él se desarrollan los vegetales, que proporcionan fuentes de energía para toda la cadena alimentaria, garantizando la supervivencia de varias especies. El suelo es un componente del paisaje de gran valor para la existencia de los seresvivos, sin embargo la enseñanza de esta asignatura no ha recibido la debida importancia en las escuelas y ha sido poco abordada. Este estudio tiene un valor enorme, porque además de desarrollar aprendizajes sobre la importancia de los suelos, promueve la conservación.

Palabras Clave: Educación, Enseñanza de la Geografía, Suelo, Vegetación

\section{INTRODUÇÃO}

O solo é a base de toda a vida no planeta e todos os seres vivos dependem dele para sobreviverem de forma direta ou indireta. Ele também é responsável por fornecer nutrientes para a terra proporcionando o desenvolvimento da agricultura para o sustento da humanidade, sendo de extrema importância protege-lo e conserva-lo, conforme (Coelho e Terra, 2001). O solo é o resultado da junção e as transformações entre o clima e os organismos que vivem sobre uma determinada matéria frequentemente originária de rochas presentes em diferentes paisagens e relevos. Durante um certo tempo os elementos (rocha, clima, organismo, relevo e tempo) são nomeados de fatores de formação de solo (Coelho e Terra, 2001).

O solo é uma camada superficial da crosta terrestre, um composto de materiais minerais e orgânicos. São vários os fatores que atuam na formação do solo: temperatura, vento, águas correntes, tipo de topografia, chuva, cobertura vegetal, tipo de rocha matriz (rocha que origina o solo) etc. (COELHO, TERRA, P.41. 2001).

A ação de vários processos sobre o solo como as perdas e acréscimos de sedimentos, transformações químicas e transporte, origina novos solos e os nutri gerando uma transformação da rocha, sendo assim construindo a partir das suas transformações nas camadas de solos com diferenças entre si, na espessura, conteúdo de matéria, nutrientes de plantas, cor 
e granulometria.

Coelho e Terra (2001) argumenta que a atuação dos processos como a adição, perdas, transportes e transformações no solo foi originando os diferentes tipos de solos e componentes minerais existentes hoje. Processo que levou longos anos e criou diferentes tipos de solos, composições e aparência por ação de agentes físicos, químicos ou biológicos a integração e a decomposição de elementos orgânicos tanto animal como vegetal dão fertilidade ao solo.

Giambelluca (2002) diz que a cobertura vegetal são tipos ou formas de vegetação de origem natural ou plantada pelo homem que recobrem um determinado espaço no qual é de extrema importância para proteção do meio ambiente. A cobertura vegetal funciona como uma espécie de telhado diminuindo o impacto, como por exemplo causado pelas chuvas e ventos, protegendo o solo da erosão e desertificação ao proteger o solo e as raízes das arvores equilibrando a temperatura.

Segundo o Ibama (Instituto Brasileiro do Meio Ambiente e Recursos Naturais), a cobertura vegetal é fortemente influenciada por variações sazonais dadas por características da fenologia vegetativas das espécies, que são variações na quantidade de folhas das espécies. A perda de solo e os elementos que lhe são associados, podem causar danos ambientais, como o assoreamento e a eutrofização de cursos d'água, além de prejuízo econômico ao produtor e à sociedade.

Foi elaborada uma aula explicativa e compreensível para os alunos do $1^{\circ}$ Ano do ensino médio da Rede Estadual da Cidade de Salgueiro - PE, acerca da importância da cobertura vegetal no processo de erosão e desertificação do solo. Neste contexto, o presente trabalho tem como objetivo avaliar a importância da cobertura vegetal para o meio ambiente, tanto para nós seres humanos como para os solos de maneira geral, a partir da análise das formas de degradação do solo. Para realizar o presente trabalho, inicialmente foi feita uma pesquisa bibliográfica em materiais nacionais e meios digitais.

\section{FUNDAMENTAÇÃO TEÓRICA}

A conservação do solo é o conjunto de práticas agrícolas destinadas a preservar a fertilidade química e as condições físicas e microbiológicas do solo. Como também o uso de técnicas agrícolas que prioriza o manejo correto das terras cultiváveis, evitando a erosão em todas suas formas. Tendo como foco aproveitar ao máximo a terra, assim, evitando-se a degradação física, química e biológica do solo.

O solo sempre foi um recurso importante na história da humanidade.Não foi à toa que 
as primeiras civilizações se estabeleceram às margens de importantes rios (Nilo, Tigres e Eufrates), haja vista que, às margens dos rios, os solos são extremamente férteis. No entanto, esse recurso, tão essencial para o homem, vem sofrendo sérios impactos decorrentes de uma ação predatória (COELHO;TERRA, P.41, 2001).

O principal objetivo da conservação do solo é manter a produtividade de sua situação inicial ou de buscar formas para recuperá-lo, quando sua produção é baixa. Utilizando-se meios de manipulação eficientes para controlar a ação dos agentes responsáveis pela erosão e degradação do solo. As medidas para preparo do solo é o uso de cobertura morta, o plantio em nível e a redução do uso de máquinas e implementos.

A utilização de leguminosas para melhorar o solo ajudam a conservar o solo, por ter como princípios em obter a máxima totalidade do nitrogênio que necessitam por meio da simbiose com bactérias específicas, elas apresentam raízes geralmente ramificadas e profundas, as estabilizando-as no solo algumas das principais leguminosas usadas para obter essa finalidade é o feijão-de-porco (Canavalia ensiformis), a soja perene (Glycine javanica), a leucena (Leucaena leucocephala) e o guandu (Cajanus cajan).

As consequências que os processos erosivos têm causado, tanto no meio rural quanto no meio urbano, tem provocado, nos últimos anos, uma intensa investigação e debate no meio acadêmico sobre os parâmetros e mecanismos responsáveis pela erosão e possíveis medidas a serem adotadas para a prevenção e controle das áreas afetadas (NUMMER E SANT'ANA, p.199, 2010).

A conservação do solo para agricultura e pecuária, necessita de um conjunto de práticas para promover a utilização sustentável do solo para a utilização pelo homem. A compactação, a erosão e o aumento da salinidade do solo estão sendo um dos maiores desafios relativos ao manejo inadequado sendo interligada com a falta de alimentos num futuro próximo, resultando em uma enorme desorganização do sistema produtivo caso as práticas corretas não forem implementadas.

Giambelluca (2002), A população mundial estar em quase 8 bilhões de pessoas, exigindo que a humanidade crie mais terras produtivas para disponibilizar pelo menos 1 bilhão de hectares de área agricultável. As áreas com manuseamento inadequado diminuem expressamente seu poder de produção, procurasse atualmente formas de trabalho que busque a renovação e aprimoramento das técnicas produtivas. Com foco em observar que os recursos são limitados, não podendo ser desperdiçados. "O poder erosivo da água depende do yolume e velocidade do escoamento, da espessura da lâmina d'água, da declividade e comprimento da vertente e da presença de vegetação" (MAGALHÃES, P.38, 1995).

A conservação do solo busca evitar a erosão no qual é o processo de desprendimento e arraste acelerado das partículas constituintes do solo. O referido processo é originado pela água 
e pelo vento, tornando-se um dos principais fatores de enfraquecimento dos solos. A erosão ocorre ao longo de milhares de anos transformando as paisagens, sendo-as intensificadas pela atividade humana. $\mathrm{O}$ uso e o manejo incorretos da terra expõem o solo ao sol, chuvas, ventos e a outros intemperismos físicos.

Segundo relatório de 2015 da Organização das Nações Unidas para a Alimentação e Agricultura (FAO), a degradação é um problema grave que atinge 33\% das terras no mundo todo. O clima tropical e subtropical brasileiro, com chuvas frequentes, causa a erosão hídrica, principal fonte de degradação dos solos. Ao decorrer da intensidade do processo erosão, e da degradação do solo, podem ocorrer outros problemas que levam à baixa produtividade. Consequentemente todos os desafios de produção agrícolas podem estar associados, tendo como as principais causas aquelas vinculadas ao uso, manejo e à conservação do solo e seus resultados no processo erosivo.

\begin{abstract}
Vastas áreas estão sujeitas à degradação do solo, às vezes de forma irreversível, por uma série de processos como erosão e desertificação acelerada, compactação e selamento, salinização, acidificação, diminuição da matéria orgânica e da fertilidade do solo e redução da biodiversidade (LAL, P. 60, 1994).
\end{abstract}

A existência da erosão pode desencadear diversos problemas como a poluição e assoreamento dos mananciais, além de causar prejuízos na produção, ocasionado pelo desgaste do solo e ao deslocamento dos resíduos agrícolas. O uso e manejo inadequados do solo reduzem também a cobertura vegetal e a infiltração da água no solo, ocasionando o escorrimento superficial e gerando a erosão.

Os solos arenosos são naturalmente frágeis, em especial os Neossolos Quartzarênicos, permitindo que os processos erosivos lineares se instalem neles com maior rapidez do que nas áreas que comportam Latossolos ou Argissolos, mais estáveis fisicamente (SÃO PAULO, P.23, 1989).

No Brasil a perda da camada superficial do solo é um dos grandes responsáveis pela degradação por um conjunto de processos como por exemplo a erosão, desertificação, compactação, salinização, acidificação, diminuição da matéria orgânica e da fertilidade do solo e redução da biodiversidade. A estrutura dos solos arenosos é fraca, pouco produtiva e constituída por grãos de areias comuns. Quando chove sobre os solos arenosos, os sais minerais que servem de nutrientes para as plantas escorrem junto com a água os deixando pobres em nutrientes.

Giambelluca (2002), fala sobre o potencial valor de uma terra sempre foi a fertilidade do solo para a sua utilização. Esse valor já era conhecido há muitos anos atrás. Um exemplo disso eram os chineses que há mais de 3000 a.c, chegaram a repartir suas terras de acordo com 
a produtividade agrícola. A taxação de impostos era entorno do tamanho do tamanho da sua produtividade e a fertilidade do solo. E para os romanos o solo era dividido em nove tipos e de acordo com suas classificações a de maior fertilidade se devia a sua cor escura, cor dada pelos Húmus que é a matéria orgânica depositada no solo, causada pela decomposição de animais e plantas mortas.

\begin{abstract}
O solo é uma camada viva, em processo permanente de formação, através da alteração das rochas e de processos pedogenéticos. Este processo é contrabalançado pelo processo de erosão, que remove seus constituintes, sobretudo pela ação da água de chuva. Portanto, há um quadro dinâmico, no qual diversos processos atuam de forma contraditória, formando e erodindo o solo, refletindo certo equilíbrio na natureza, no qual a erosão é considerada normal. (GOMES, p. 38, 2001).
\end{abstract}

Com a ação do homem, causadas pelas diversas práticas inadequadas de uso e manejo do solo, o ser humano provocou o agravamento da erosão e a degradação dos solos. Podemos expor algumas práticas inadequadas de uso e manejo do solo como o desmatamento, as queimadas, o manejo incorreto do solo, exploração excessiva, a não utilização de terraceamento e entre outras.

A degradação do solo está relacionada com sua destruição. Por exemplo a erosão, o enfraquecimento de um terreno, a contaminação da terra e a sua desertificação são alguns dos problemas mais graves ocasionados pela degradação. As suas degradações ocorrem normalmente em áreas de monocultura, de desmatamento e áreas desérticas, sendo altamente importante a cobertura vegetal sendo primordial não só para a preservação dos mananciais e reservas hídricas, mas também para a conservação do solo. Um solo sem vegetação para protege-lo torna-se vulnerável a problemas de erosão e degradação.

O desmatamento predatório e muitas vezes de forma ilegal acarreta diversos problemas ao solo, sendo que umas das finalidades da vegetação é dá um suporte como proteção ao terreno. Com a grande necessidade de expansão de áreas para o cultivo, as pastagens e as criações de gado geram uma ocupação desordenada que são umas das principais causas de desmatamento no Brasil.

A vegetação tem um grande papel ambiental, onde permite a proteção da biodiversidade, dos mananciais de água, estabilização de encostas, restabelecimento da paisagem, barreiras contra o vento, equilíbrio climático, recuperação do solo, controle de poluição, entre outros. "A presença de florestas nativas pode desempenhar diversas funções eco hidrológicas, como a regulação da quantidade de água, o controle da erosão e aporte de sedimentos e, consequentemente, influenciando os parâmetros físico-químicos dos cursos d'água. " (Lima et al.,P 17, 2013). 
Pode ser citado alguns fatores contribuintes para o desmatamento, são eles, a expansão da fronteira agrícola, quase sempre associada as queimadas, a mesma acarreta grandes prejuízos ambientais, os assentamentos contribuem para o desmatamento, devido as inúmeras construções serem irregulares e acompanhadas de grilagem de terras, a pecuária necessita desmatar e limpar seu terreno para obtenção de pastos, assim prejudicando o terreno, e a ação das queimadas, a construção de casas e cidades e as ocupações irregulares.

Essas florestas nos topos de morros interceptam a água da chuva, ao mesmo tempo que a presença de serapilheira protege o solo do impacto direto das gotas de água, impedindo a erosão, a lixiviação e a compactação do solo. (GIAMBELLUCA, 2002; LIMA et al., 2013; SAYER, 2006). A vegetação presente sobre o solo serve como proteção para o mesmo, sobre os eventos externos impactantes no solo.

A erosão consiste no processo de desgaste, transporte e sedimentação das rochas e dos solos causada pelos efeitos da ação dos fatores erosivos, como a água, ventos e os seres vivos. A desagregação das partículas de rochas sedimentarias é ocasionada pela ação do intemperismo que são os conjuntos de processos químicos, físicos e biológicos que provocam o desgaste dos solos e rochas. A erosão muitas vezes provoca a poluição e o assoreamento dos mananciais, a mesma pode causar prejuízos diretos na produção, devido ao desgaste do terreno e ao arraste dos insumos agrícolas. $\mathrm{O}$ transporte desses sedimentos ocorre pela ação da gravidade e dos elementos da superfície, já a sedimentação consiste na deposição das partículas dos ambientes erodidos.

O uso e manejo inadequado do solo reduzem também a cobertura vegetal e a infiltração da água no solo, acelerando o processo de desertificação, desfigura as paisagens naturais, aumenta a perda do solo, e destruindo a fauna e a flora, entre outras. (Figura 1).

Figura 1: "Efeitos da Erosão".

Baixa produtividade

Degradação do solo
Poluição de mananciais

\section{Erosão do solo}

Enchentes

e assoreamento

de mananciais 
Podemos classificar as erosões conforme os agentes erosivos, a seguir uma lista dos processos erosivos pela forma como eles ocorrem.

- Erosão Pluvial: É ocasionada pela água das chuvas no solo. Em fraca intensidade, a chuva provoca apenas a lavagem dos solos, mas, em maiores intensidades, provoca erosões pluvial em áreas desprotegidas de vegetação.

○ Erosão Fluvial: Ocasionada pela água dos rios ao longo de seu curso, alterando o seu curso para vales mais profundos do que a sua volta. Quando existe uma vegetação nas margens dos rios, elas são desgastadas pela ação das águas, deixando as margens mais suscetíveis ao processo erosivo.

- Erosão Marinha: É ocasionada pela deterioração das rochas e solos litorâneos por ação da água do mar, favorecendo para a formação de praias e de paisagens costeiras.

○ Erosão Eólica: Ocasionada pela força dos ventos, no qual provoca o intemperismo das rochas e a atuação no transporte de sedimentos para regiões mais distantes dos locais de erosão. Frequentemente é um processo mais lento do que os outros que envolvem a ação da água.

○ Erosão Glacial: É ocasionada pelo congelamento dos solos e o deslocamento em forma de blocos. Com o congelamento da água ela tende-se a se dilatar e provocar alterações na composição e disposição das rochas e também dos solos.

○ Erosão Gravitacional: Frequentemente ocorrem em localidades muito inclinadas, em áreas montanhosas de acentuada declividade. Consiste na quebra e transporte de sedimentos ocasionadas pela ação da gravidade, com a deposição das partículas de rochas das partes mais altas para as partes mais baixas de uma determinada região.

○ Erosão geológica: É aquela que não sofreu nenhuma interferência humana/A mesma age redesenhando ou modelando as paisagens, com a junção de yários outros tipos de ações erosivas. Vale ressaltar que a voçoroca pode ser um resultado das diversas combinações dos diferentes tipos de erosão, assim, dando ao surgimento das grandes crateras nos solos.

A desertificação é o processo de degradação das terras nas zonas áridas, semiáridas e subúmidas secas, resultante da ação de vários fatores, dentre os quais se destacam as variações 
climáticas e as atividades humanas (BRASIL, 1999). A degradação do solo é uma consequência das ações naturais que podem ser ocasionadas pela ação do homem como fatores do mesmo.

O processo de degradação dos solos acarreta a degradação da cobertura vegetal, do solo e dos recursos hídricos. Originados pelos diversos processos físicos, químicos e hidrológicos essa deterioração provoca a destruição na forma biológica das terras quanto da capacidade delas em sustentar a população viventes naquela região.

O Plano Nacional de Combate à Desertificação (PNCD) estima que cerca de 181.000 $\mathrm{km}^{2}$ (20\% da área semiárida do Nordeste) encontra-se em processo de desertificação (Brasil, 1998), problema que se vem agravando em decorrência das secas sucessivas que assolam o Nordeste e, principalmente, das pressões antrópicas em um ecossistema tipicamente frágil (ACCIOLY, 2000).

No Brasil as áreas semiáridas representam um enorme desafio para o aumento da produtividade e o desenvolvimento dos recursos naturais por causa das suas irregulares precipitações pluviométricas, fertilidade dos solos e moradias de pessoas em ambientes frágeis. "Ocorre como um processo cumulativo de deterioração das condições ambientais que, em um estádio mais avançado, afeta as condições de vida da população.” (SAADI, P.55, 2000). Atualmente o tal problema estar se agravando devido as recorrentes secas que assolaram o Nordeste nos últimos anos.

\footnotetext{
Quanto à intensidade, o fenômeno encontra-se concentrado em pontos específicos do bioma Caatinga, como um todo, resulta de um conjunto de procedimentos exploratórios ecologicamente incorretos e sua gravidade se expressa por meio da degradação conjunta de ativos ambientais, como solo, biodiversidade e recursos hídricos (CNRBC, P. 39, 2004).
}

Em quase toda parte do semiárido, as áreas apresentam solos rasos e com cobertura vegetal esparsa oriundas de caatinga hiperxerófila. Diante destas condições e locais onde os ecossistemas são dependentes de precipitações, a perda de solo por erosão é um grande fator que acarreta em perdas das terras produtivas do semiárido. No Nordeste, as áreas que apresentam altos níveis de degradação ambiental estão atualmente ocupadas por solos não cálcicos em que apresentam forte sensibilidade à erosão.

\section{METODOLOGIA}

A presente pesquisa tem natureza qualitativa, exploratória e descritiva visando uma maior familiaridade com o tema proposto aos discentes. A coleta de dados foi feita através de pesquisas bibliográficas. Como fonte de informação conta com pesquisa bibliográfica e de 
campo e o método de abordagem é o indutivo. O campo de pesquisa foi em uma Escola da Rede Estadual, localizada na Cidade de Salgueiro/PE, onde aconteceu o $1^{\circ}$ Simpósio do Meio Ambiente "Redescobrindo a Caatinga" tendo como sujeitos estudantes das turmas de $1^{\circ}$ e $2^{\circ}$ ano do ensino médio. Como o simpósio trata de assuntos científicos e acadêmicos, fui indicado para ministrar uma aula de 60 minutos como o tema a importância da cobertura vegetal no processo de erosão e desertificação do solo. Dos 30 alunos inscritos para a reunião, todos cursavam o $1^{\circ}$ ano. Com auxílio de Datashow como instrumento de ensino, coube-me buscar conhecer e dominar esses recursos para introduzi-los na aula utilizando a favor do ensino aprendizagem. Foi possível ter uma "aula expositiva dinâmica", onde os alunos ficaram motivados pelo tema e expuseram seus questionamentos acerca do assunto em questão. Também foram realizados questionamentos sobre o tema com o intuito de identificar as principais dúvidas dos estudantes diante da importância da conservação do solo. Foi observado e identificado as dúvidas dos estudantes acerca do tema e posteriormente esclarecidos.

\section{RESULTADOS E DISCUSSÃO}

Conforme a (Figura 2) ilustra, a aula foi elaborada com introdução ao tema "A importância da cobertura vegetal no processo de erosão e desertificação do solo', para o compor o $1^{\circ}$ Simpósio do meio Ambiente, na Escola de Referência em ensino Médio Carlos Pena Filho.

Figura 2: I Simpósio do Meio Ambiente “ Redescobrindo a Caatinga. ”

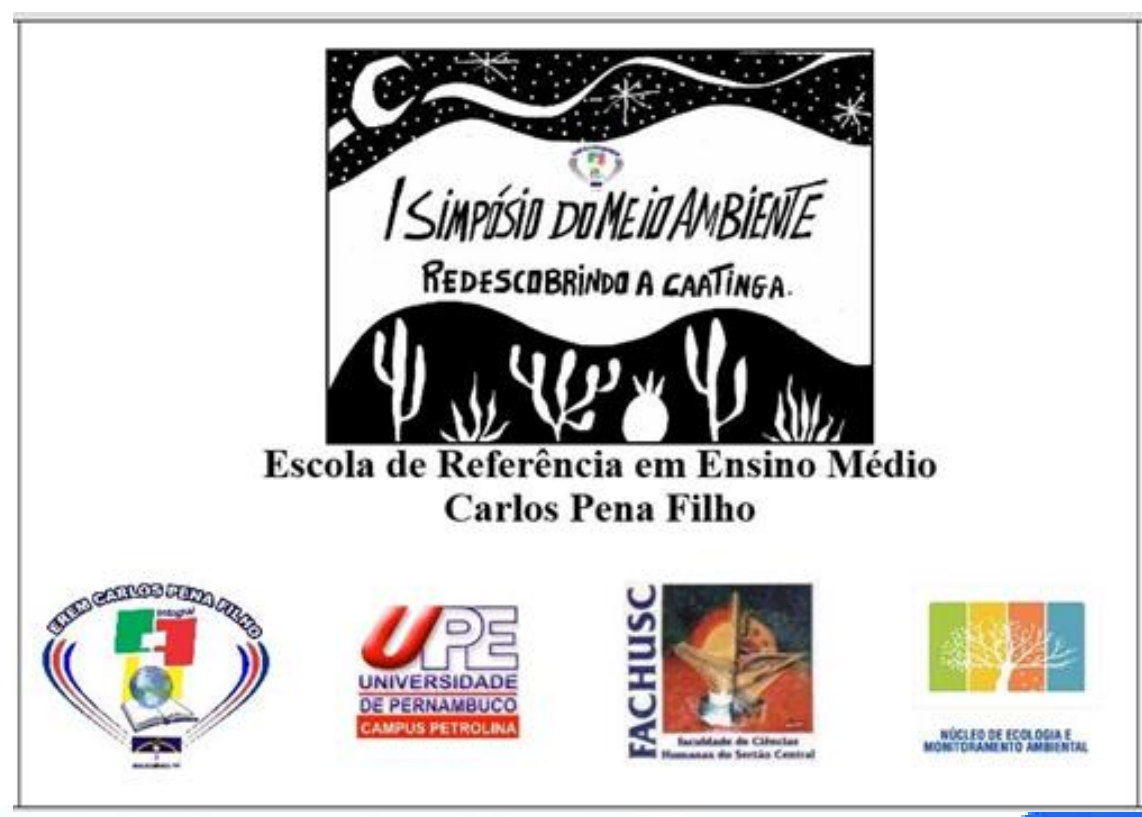

Fonte: EREM Carlos Pena Filho. 
Diante disso, todos os alunos inscritos para a reunião tiveram o contato com o assunto, conhecendo a dinâmica dos solos, onde foi apresentado opiniões e pontos de vista sobre o tema em discussão, conforme a (figura 3).

Figura 3: Aula "A importância da cobertura vegetal no processo de erosão e degradação do solo. "

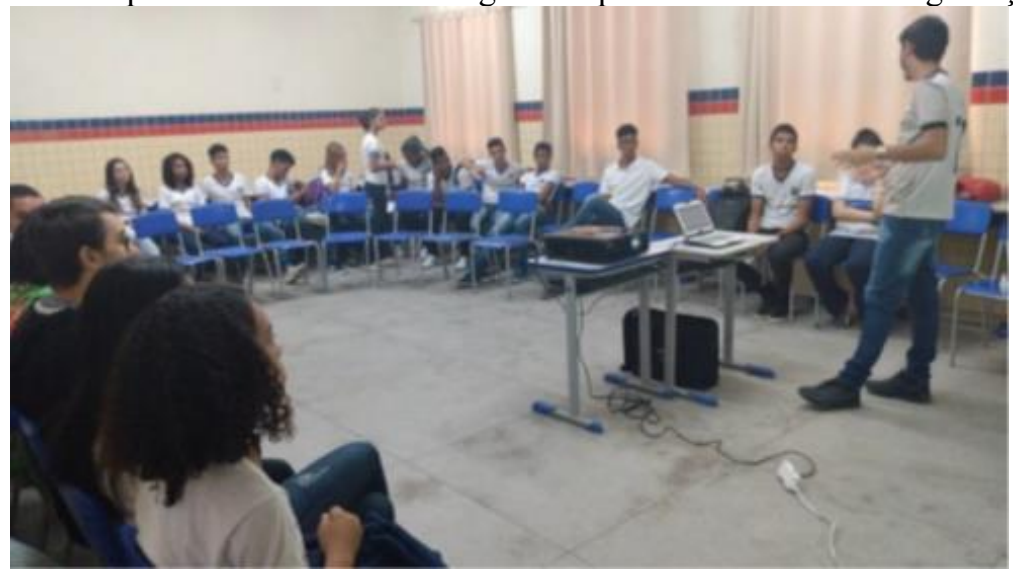

Fonte: Própria (2019).

Castrogiovanni (2007), relata que as práticas didáticas nas escolas devem ser aplicadas de uma forma lúdica, inquietante que desperte a curiosidade dos discentes, envolvendo o sujeito e transformando seu estado intelectual. De início evidenciamos um prévio e considerável conhecimento acerca da conservação do solo e da vegetação. A aula teve como objetivo ensinar aos alunos conceitos e informações sobre a conservação do solo. Sendo que ao notarmos o entendimento dos estudantes pelo assunto abordado em sala, começamos a debater o tema.

Além de perguntas, se obteve respostas relevantes por parte dos estudantes em relação ao manejo e conservação do solo (Figura 4). Ao perguntarmos sobre o que era a erosão e seus principais agentes, boa parte destes souberam definir muito bem, seguindo com comentários sobre essa prática nos seus locais de vivência, ou seja, atividades essas encontradas no semiárido, sobre a vegetação e solo, exibindo uma ótima base de conhecimento.

Figura 4: "Debate Sobre Vegetação x Conservação do Solo."

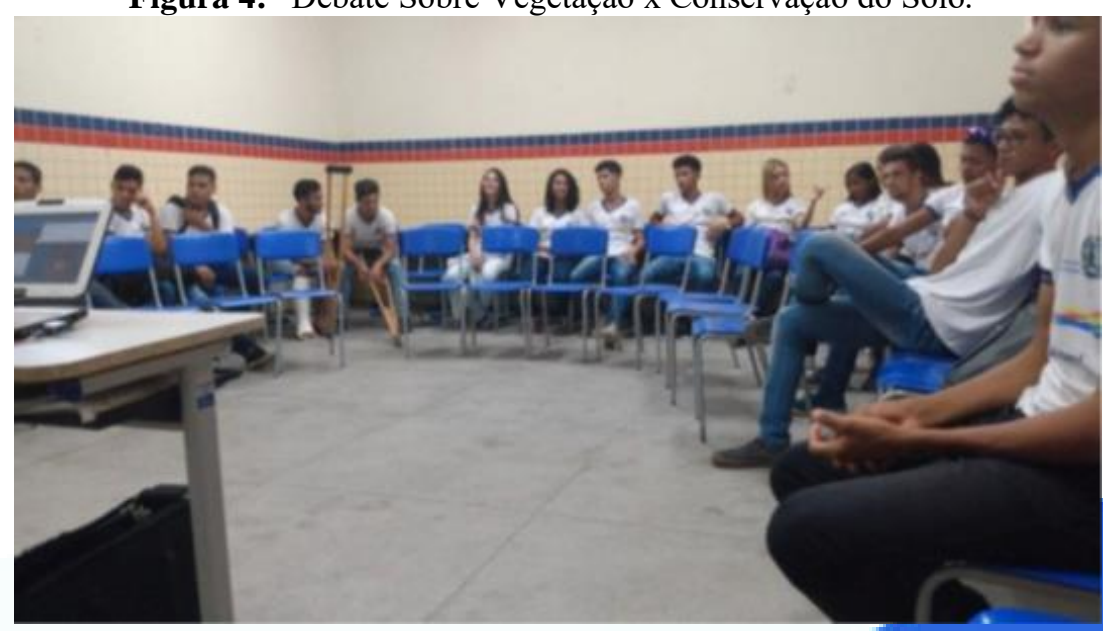

Fonte: Própria (2019).

[188] 
A renovação do ensino de Geografia, segundo Kaercher (2004) será conquistada na medida em que o professor tenha uma formação plena, que leve em conta a integração do conhecimento geográfico e pedagógico para o ensino escolar. O corrente artigo ressalta a extrema relevância dos estudantes terem o aprendizado em geografia, a partir do contato com os diversos elementos e ocorrências onde vivem. Sendo de grande importância que os alunos sejam inspirados e desafiados para que possam compreender e repassar esses tipos de conhecimento, aprender os diversos acontecimentos no planeta tanto no natural como no social.

A pesquisa teve como intuito proporcionar a turma bases sólidas para a percepção individual sobre a manutenção da cobertura vegetal para a preservação dos mananciais e reservas hídricas, mas também para a conservação do solo, além de classificar ações a partir do uso do solo, conforme (Tabela 1).

Tabela 1: Classificação da superfície do solo a partir do uso.

\begin{tabular}{|c|c|}
\hline CLASSIFICAÇÃ̃O & TIPO \\
\hline Mudança da superfície. & $\begin{array}{l}\text { Desmatamento. } \\
\text { Reflorestamento. } \\
\text { Impermeabilização. }\end{array}$ \\
\hline Uso da superfície. & $\begin{array}{l}\text { Urbanização. } \\
\text { Reflorestamento para exploração } \\
\text { sistemática. } \\
\text { Desmatamento: extração de madeira, cultura } \\
\text { de subsistência, culturas anuais, culturas } \\
\text { perenes. }\end{array}$ \\
\hline Método de alteração. & $\begin{array}{l}\text { Queimada. } \\
\text { Manual. } \\
\text { Equipamentos. }\end{array}$ \\
\hline
\end{tabular}

Fonte: Própria (2020).

Podemos considerar que a vegetação tem um importante objetivo ambiental, visto que permite a proteção da biodiversidade, dos mananciais de água, conectividade entre fragmentos florestais, estabilização de encostas, restabelecimento da paisagem cênica, barreiras contra o vento, equilíbrio climático, captura de carbono, recuperação do solo, controle de poluição, entre outros.

\section{CONCLUSÕES}

Na agricultura e na pecuária, a conservação do solo é valiosíssima, o solo é um dos recursos naturais mais importantes da natureza, pois exerce funções ambientais essenciais à vida. São os conjuntos de práticas efetivas para proporcionar o uso adequado e sustentável do 
solo para a semeadura, compactação, a erosão e alta salinidade do solo são um dos grandes problemas relacionados ao manejo inadequado tendo a relação direta com a falta de alimentos no futuro. Sucedendo em um profundo desequilíbrio do sistema produtivo se as práticas corretas não forem desenvolvidas. A degradação das condições do solo é um processo significativo, por dificilmente ser reversível, visto que os processos de formação além de regeneração ocorrem de forma predominantemente lenta. (SOMBROEK, SENE, 1993).

Para a conservação do solo, deve-se ser elaborado um planejamento em conjunto com os profissionais das ciências agrárias e ambientais, para a conservação do solo e sua utilização. É de extrema importância observar o processo de produção de uma forma geral, deve-se ser encarado problema como um todo e não em partes. Sendo de suma importância observar os custos econômicos envolvidos e os preços pagos pelo mercado, o retorno financeiro é muito pouco e assim desencadeia vários fatores que fazem acontecer o abandono dos terrenos pela não cobertura vegetal. Atualmente existem práticas que são essenciais para a recuperação e conservação dos solos, são elas, a aplicação de adubos orgânicos, cumprimento das regras e padrões necessários para o domínio e a diminuição das erosões, aumentar a deposição de nutrientes orgânicos no solo a partir da manutenção da biodiversidade e da vegetação do solo, utilização do adubo verde, e o plantio com rotação de culturas.

Souza (2007, p. 110) ressalta que "[...] é possível a utilização de vários materiais que auxiliem a desenvolver o processo de ensino e de aprendizagem, isso faz com que facilite a relação professor - aluno - conhecimento.” É possível notar a importância da utilização de recursos didáticos no processo de ensino aprendizagem nas questões de solo. Os recursos podem possibilitar a aprendizagem dos alunos de forma mais significativa, e o aluno acaba tendo maior interesse pelas aulas, tornando o processo de aprendizagem mais fácil e criando ambientes de aprendizagem mais dinâmicos, possibilitando que os alunos compreendam melhor os conteúdos e que, de forma interativa e dialogada, possam crescer os seus conhecimentos.

\section{REFERÊNCIAS}

ACCIOLY, L.J.O. Degradação do solo e desertificação no Nordeste do Brasil. B. Inf. SBCS, 25:1:23-25, 2000.

BRASIL. Conselho Nacional do Meio Ambiente (CONAMA). Resolução CONAMA nº 238 de

22 de dezembro de 1997. Diário Oficial da União, Brasília, DF, 23 dez. 1997, nº 248, p. 30.930.

Disponível em: <http://www.areaseg.com/conama/1997/238-1997.pdf>. Acesso em: $12 / 11 / 2020$. 
CASTROGIOVANNI, A.C. Ensino da geografia: caminhos e encantos. Porto Alegre: EDIPUCRS, 2007.

COELHO, M. A. de; TERRA, L. Geografia Geral: O espaço natural e socioeconômico. São Paulo: Moderna, 2001.

\section{CONSELHO NACIONAL DA RESERVA DA BIOSFERA DA CAATINGA - CNRBC.}

Cenários para o Bioma Caatinga. Recife, Secretaria de Ciência, Tecnologia e Meio Ambiente, 2004. 283p.

GIAMBELLUCA, T. W. Hydrology of altered tropical forest. Hydrological Processes, v.16, n.8, p.1665-9, 2002.

GOMES, F. S.. Estudo da Erodibilidade e Parâmetros Geotécnicos de um solo em Processo Erosivo. Tese de Doutorado. Dissertação de Mestrado. UFPE. Engenharia Civil, Recife-PE. 2001.

KAERCHER, N. A. A geografia escolar na prática docente: a utopia e os obstáculos epistemológicos da Geografia Crítica. São Paulo. 2004. 363f. Tese (Doutorado em Geografia Física) - Faculdade de Filosofia, Letras e Ciências Humanas, Universidade de São Paulo, São Paulo, 2004.

LAL, R. Methods and guidelines for assessing sustainable use of soil and water resources in the tropics. Columbus: Ohio State University, Department of Agronomy, 1994. 78 p. (SMSS Technical Monograph, 21).

LIMA, W. de P.; FERRAZ, S. F. de B.; FERRAZ, K. M. P. M. Interações bióticas e abióticas na paisagem: uma perspectiva eco-hidrológica. In: CALIJURI, M. do C.; CUNHA, D. G. F. (Ed.) Engenharia ambiental: conceitos, tecnologia e gestão. Rio de Janeiro: Elsevier, 2013. p.215-44.

MAGALHÃES, R. A. Processos erosivos e métodos de contenção. Ouro Preto: CEEB, 1995.

NUMMER, A.V.; SANT'ANA, K.D. A. ESTUDOS SOBRE PROCESSOS EROSIVOS NA GEOGRAFIA BRASILEIRA:PERÍODO: 2004, 2010. Disponível em: <http://w3.ufsm.br/ppggeo/files/ebook01/Art.11.pdf>. Acesso em: 05/11/2020.

SAADI, A. Os sertões que viram desertos. B. Inf. SBCS, 25:1:10- 17, 2000.

SÃO PAULO. Secretaria de Energia e Saneamento. Departamento de Águas e Energia Elétrica. Controle de erosão: bases conceituais e técnicas; diretrizes para o planejamento urbano e regional, orientações para o controle do boçorocas urbanas. São Paulo: DAEE/IPT, 1989. 92 p.

SAYER, E. J. Using experimental manipulation to assess the roles of leaf litter in the functioning of forest ecosystems. Biological Reviews, v.81, n.1, p.1-31, 2006.

SOMBROEK, W. \& SENE, E.H. Land degradation in arid, semi-arid and dry sub-umid areas: Rainfed and irrigated lands, rangelands and woodlands. Disponível em <http://www.fao.org/documents/show_cdr.asp?url_file=/docrep/X5308E/X5308E00.htm> 
Acesso em outubro. de 2020.

SOUZA, S. E. O uso de recursos didáticos no ensino escolar. In: I ENCONTRO DE PESQUISA EM EDUCAÇÃO, IV JORNADA DE PRÁTICA DE ENSINO, XIII SEMANA DE PEDAGOGIA DA UEM, Maringá, 2007. Arq. Mudi. Periódicos. Disponível em: <http://www.pec.uem.br/pec_uem/revistas/arqmudi/volume_11/suplemento_02/ artigos/019.df>. Acesso em: 13. 11. 2020 